\title{
Measurement of sulphated glycosaminoglycans and proteoglycan fragments in arthritic synovial fluid
}

\author{
GRAEME CARROLL
}

From the Department of Rheumatic Diseases, Royal Perth (Rehabilitation) Hospital, Shenton Park, Western Australia

SUMMARY Immunoreactive proteoglycans (iPGs) and sulphated glycosaminoglycans (GAGs) were assayed in synovial fluid obtained from 22 patients with osteoarthritis (OA), 21 with rheumatoid arthritis (RA), 13 with gout, and five with Reiter's syndrome. A strong positive linear correlation was observed between concentrations of sulphated GAGs and iPGs in RA $(r=0.95)$ and gout $(r=0 \cdot 94)$. A linear correlation was also observed in OA $(r=0 \cdot 65)$. Patients with gout and Reiter's syndrome had significantly higher concentrations of sulphated GAGs and iPGs than patients with OA or RA. Patients with gout also had significantly higher total quantities of sulphated GAGs and iPGs in the knee joint cavity than patients with OA or RA. In all four diseases similar profiles were observed when comparisons were made between the total quantities and concentrations of sulphated GAGs and iPGs in synovial fluid. These results indicate that the observed differences in concentrations are not simply a function of dilution. The concentrations of sulphated GAGs and iPGs did not correlate closely with the type or number of inflammatory cells in the synovial fluid. Considerable variation was noted in the sulphated GAG/iPG ratios, suggesting that different mechanisms may be contributing to the release of proteoglycans in the diseases studied.

Key words: rheumatoid arthritis, osteoarthritis, gout, Reiter's syndrome, leucocytes, cartilage.

The two principal macromolecular constituents of articular cartilage are proteoglycans and collagen.' The proteoglycans are mostly bound to hyaluronic acid, forming large aggregates which are enmeshed in the collagen network. 'Monomeric proteoglycans consist of a long protein core to which the glycosaminoglycans (GAGs) are covalently attached. ${ }^{1}$ The major GAGs in adult cartilage are chondroitin-6-sulphate and keratan sulphate. ${ }^{2}$ Chondroitin sulphate generally predominates, but there is an increased proportion of keratan sulphate with advancing age. ${ }^{3}$ Chronic arthritic diseases are characterised by deformity and loss of joint function. To a large degree these sequelae are consequences of cartilage resorption. Precisely how cartilage is degraded in such diseases is unknown. Histopathological studies of arthritic cartilage have shown evidence of proteoglycan depletion in early

Accepted for publication 24 April 1988.

Correspondence to Dr Graeme Carroll, Department of Rheumatic Diseases, Royal Perth (Rehabilitation) Hospital, Selby Street, Shenton Park, 6008 Western Australia. disease, and studies of cartilage explants have shown that loss of proteoglycans is an early feature of matrix resorption. ${ }^{4}$ Recently, a number of investigators have reported the presence of GAGs and proteoglycans in synovial fluid..$^{6-13}$ These molecules can be measured by immunochemical methods. It should be noted that this approach relies upon the conservation of antibody binding sites, which cannot be guaranteed in inflamed joints where proteolytic enzymes are likely to be active. An alternative approach involves the measurement of sulphated GAGs, which are less susceptible to degradation. In this study immunoreactive proteoglycans (iPGs) and sulphated GAGs have been measured in four rheumatic diseases. The respective methods are compared and the results are related to the nature and intensity of the inflammatory cell infiltrate.

\section{Materials and methods}

MATERIALS

$\mathrm{Na}^{125} \mathrm{I}$ (specific activity $509 \mathrm{MBq} / \mathrm{g}$ of iodine) was 
purchased from Amersham International plc, Amersham, UK. Chondroitin ABC lyase was obtained from the Seikagaku Kogyo Co Ltd, via Miles Laboratories, Sydney, Australia. 1,9Dimethylmethylene blue was purchased from KochLight Ltd, Haverhill, UK. Chondroitin sulphate, guanidine hydrochloride, $\mathrm{N}$-acetylcysteine, papain (type III), phenylmethylsulphonyl fluoride, and iodoacetic acid were obtained from Sigma Chemical $\mathrm{Co}$, St Louis, USA. Caesium chloride and Sepharose CL-2B were obtained from Pharmacia Fine Chemicals AB, Uppsala, Sweden. Pepstatin was purchased from Peptide Institute Inc, Osaka, Japan. Normal rabbit serum was obtained from Calbiochem Behring Diagnostics, La Jolla, USA, and donkey antirabbit serum from Wellcome Reagents Ltd, Beckenham, UK. All other chemicals were AR grade.

COLLECTION, PROCESSING, AND STORAGE OF SYNOVIAL FLUID

Synovial fluid was obtained from the knee joints of patients requiring either diagnostic or therapeutic aspiration. Diagnoses were assigned on the basis of the criteria recommended by the American Rheumatism Association. ${ }^{14-17}$ The synovial fluid was collected in plastic vials. Small samples were removed for microscopic examination. The specimens were then centrifuged at $1000 \mathrm{~g}$ for 10 minutes to remove cells and tissue debris. Supernatants were stored in aliquots at $-20^{\circ} \mathrm{C}$. Leucocyte counting was performed by standard methods using a haemocytometer.

RADIOLOGICAL ASS ESSMENT

The Larsen-Dale index and standard reference films were used to grade the severity of the arthritis in the knee joints of patients with rheumatoid arthritis (RA). ${ }^{18} x$ Rays obtained either concurrently or within one year of joint aspiration were graded by an experienced radiologist who was not aware of the clinical status of the patient or the laboratory findings.

EXTRACTION AND PURIFICATION OF

CARTILAGE PROTEOGLYCANS

Slices of macroscopically normal articular cartilage were removed from the femoral condyles of cadaveric or amputated human femurs and diced to approximately $1 \mathrm{~mm} .{ }^{3}$ The tissue was then extracted with 10 volumes of $4 \mathrm{M}$ guanidinium chloride, $0 \cdot 1 \mathrm{M}$ sodium acetate $\mathrm{pH} 5 \cdot 0$, containing $1 \mathrm{~mol} / \mathrm{l}$ concentration each of edetic acid, iodoacetic acid, and phenylmethylsulphonyl fluoride and $5 \mathrm{mg} / \mathrm{l}$ of pepstatin. Extraction was for 48 hours at $4^{\circ} \mathrm{C}$. The extracts were filtered and the residue washed with the extraction medium. $\mathrm{CsCl}$ was added to the filtrate to give a density of $1.5 \mathrm{~g} / \mathrm{ml}$ and guanidinium $\stackrel{\oplus}{?}$ chloride added so that its concentration remained at? $4 \mathrm{~mol} / \mathrm{l}$. The solution was then subjected to density gradient centrifugation at $11^{\circ} \mathrm{C}$ for 48 hours at $\frac{\text { क }}{\odot}$ $33000 \mathrm{rpm}$ in a Beckman L8-80 ultracentrifuge. The $\triangle$ gradient was fractionated and the fractions assayed $\%$ for sulphated GAGs and absorbance at $280 \mathrm{~nm}$. The $\vec{\circ}$

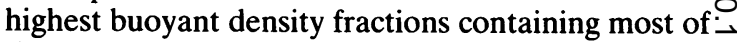
the proteoglycan subunit were pooled, exhaustively $\vec{\omega}$ dialysed against water at $4^{\circ} \mathrm{C}$, and then freeze dried.

SEPHAROSE CHROMATOGRAPHY

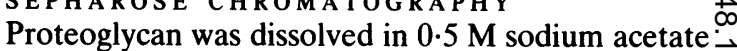
$\mathrm{pH} 6.8$ at a concentration of $0.5 \mathrm{~g} / 1$ and then subjected to chromatography on Sepharose CL-2B. 0 Samples $(1 \mathrm{ml})$ were applied to the column $\left(90 \times 0.67^{\circ}\right.$ $\mathrm{cm}$ ), which was equilibrated and eluted with $0.5 \mathrm{Mc}$ sodium acetate $\mathrm{pH} 6 \cdot 8$. The void volume of the column was determined by the elution of human proteoglycan aggregate and the total volume by elution of human proteoglycan which had been $\overrightarrow{0}$ digested with papain. Chromatography was@ performed by downward elution at room temperature with a flow of $6 \mathrm{ml} / \mathrm{h}$. Fractions $(0.5 \mathrm{ml})$ were collected and assayed for sulphated GAGs.

ASSAY FOR TOTAL SULPHATED GAGs

Total sulphated GAGs were assayed spectrophotometrically using the method of Farndale et $\overline{\mathrm{O}}$ $a l$ and the modifications previously described. ${ }^{10} 193$ Samples of synovial fluid $(0.5 \mathrm{ml})$ were diluted to $5 \frac{\text { 吾 }}{0}$ $\mathrm{ml}$ in $50 \mathrm{mM}$ phosphate buffer $\mathrm{pH} 7$, and $0.1 \mathrm{ml}$ was transferred in duplicate to polystyrene tubes. $A \stackrel{2}{\frac{2}{2}}$ further $0.1 \mathrm{ml}$ of the same buffer containing $N-\frac{2}{\sigma}$ acetylcysteine, final concentration $2 \mathrm{mmol} / 1$, and 3 . papain 0.13 units was added, and the tubes were $\delta$ capped and mixed. The samples were then incubated at $65^{\circ} \mathrm{C}$ for two hours. After digestion the 0 papain was inactivated with iodoacetic acid, final concentration $4 \mathrm{mmol} / \mathrm{l}$, and the $\mathrm{NaCl}$ concentration of the digest was adjusted to $0.5 \mathrm{~mol} / \mathrm{l}$ in a final volume of $0.25 \mathrm{ml}$. Dimethylmethylene blue dye reagent $(2.5 \mathrm{ml})$ was then added and the absorbance $\mathrm{N}$ at $525 \mathrm{~nm}$ read after 15 seconds in a Shimadzu digital ultraviolet/visible spectrophotometer. The assay was $\sigma$ calibrated with shark chondroitin sulphate and suitable solvent blanks. It was found to be linear from 0.2 to $5 \mu \mathrm{g}$. Reported results represent the mean values obtained from three assays. The between assay variation for the sulphated GAG assay was $8 \cdot 12 \%(n=12)$.

RADIOIMMUNOASSAY FOR PROTEOGLYCANS号 Radioimmunoassays were performed on diluted specimens of synovial fluid using the method de- $\varnothing$ 
scribed by Christner et al and a rabbit antiserum characterised by Kimura et al. ${ }^{2021}$ This antiserum contains antibodies which recognise epitopes on the hyaluronic acid binding region. Separation was performed by a second antibody technique using appropriate dilutions of normal rabbit serum and donkey antirabbit serum. The assay was calibrated with human proteoglycan subunit. Reported results represent the mean values obtained from three assays. The between assay variation for the radioimmunoassay was $12 \cdot 8 \%(n=10)$.

\section{STATISTICAL ANALYSIS}

The data were analysed statistically to determine whether the concentrations varied significantly (at the $95 \%$ confidence level) with respect to the disease group (Student's $t$ test, two way analysis of variance). The degree of correlation between the two diffent types of assay and between leucocyte numbers and iPG and sulphated GAG concentrations was determined by regression analysis using the method of least squares.

\section{Results}

CORRELATION BETWEEN THE ASSAYS

To compare the assays for sulphated GAGs and iPGs proteoglycan monomer purified from five different specimens of human articular cartilage was assayed by both methods over a broad range of concentrations. Five samples of normal synovial fluid were also assayed. A strong linear relation was observed between the results obtained with these methods for both the purified cartilage proteoglycans $(r=0.974)$ and the normal synovia $(r=$ $0.995)$. These results are consistent with detection of the same analyte.

The sulphated GAG/iPG ratio was determined in each specimen of purified proteoglycans (Table 1) and in the samples of normal synovial fluid (Fig. 1). The ratios ranged from 1.00 to 1.64 (mean 1.24) in the specimens of purified proteoglycans and 0.95 to 1.01 (mean 0.98 ) in the normal synovial fluid. The high degree of consistency in the results obtained for the normal synovia may be due to the presence of a relatively homogeneous population of proteoglycans in normal joint fluid.

AGE AND CONCENTRATIONS OF IPGS AND SULPHATED GAGs

The four diseases selected for study tend to affect different age groups. Whether age itself has an effect on the nature or concentration of proteoglycans in the synovial fluid is unclear. To examine this possibility the concentrations of sulphated GAGs and iPGs were evaluated in patients with osteoarthritis (OA) and RA. The results in these two diseases were combined for this analysis. Figure 2 shows that neither the concentrations of sulphated GAGs nor those of iPGs are related closely to age.

\section{CONCENTRATIONS OF IPGS}

Table 2 shows the concentrations of iPGs and total sulphated GAGs together with the volume of

Table 1 Sulphated GAG/iPG ratio for intact proteoglycan monomers purified from human articular cartilages of varying age*

\begin{tabular}{lll}
\hline Cartilage & Age (years) & Sulphated GAG/iPG \\
\hline 1 & 30 & $1 \cdot 38(0 \cdot 37)$ \\
2 & 31 & $1 \cdot 01(0 \cdot 29)$ \\
3 & 48 & $1.00(0 \cdot 28)$ \\
4 & 64 & $1 \cdot 64(0 \cdot 27)$ \\
5 & 76 & $1 \cdot 17(0 \cdot 17)$ \\
\hline
\end{tabular}

*Values are mean (SD) $(n=3)$.

$+\mathrm{GAG}=$ glycosaminoglycan; $\mathrm{iPG}=$ immunoreactive proteoglycan.

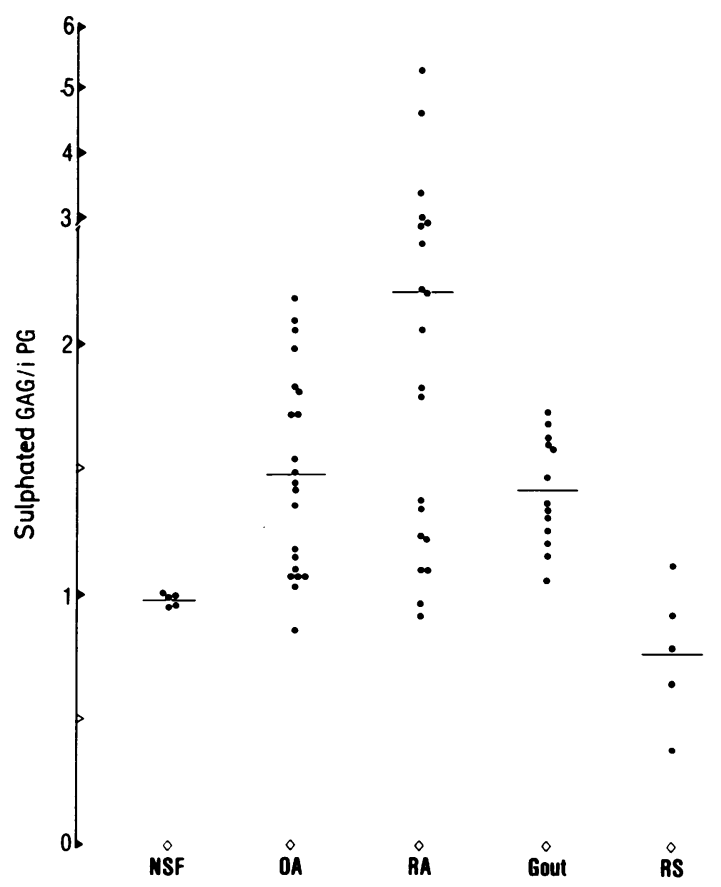

Fig. 1 Sulphated glycosaminoglycan/immunoreactive proteoglycan (GAG/iPG) ratios in the synovial fluid obtained from normal knee joints (NSF) and the knee joints of patients with osteoarthritis $(O A)$, rheumatoid arthritis $(R A)$, gout, and Reiter's syndrome (RS). Horizontal bars denote mean values. 


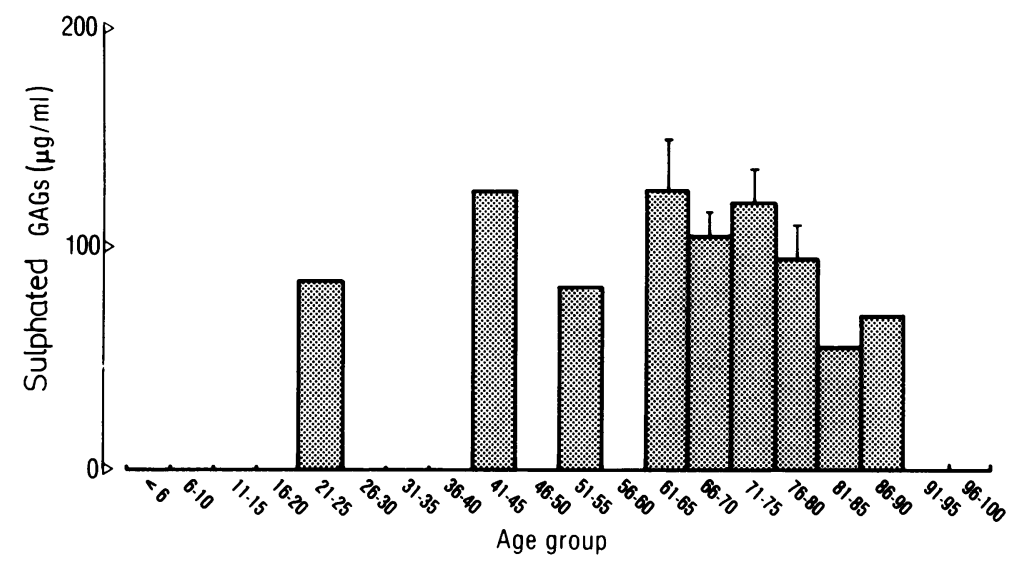

B

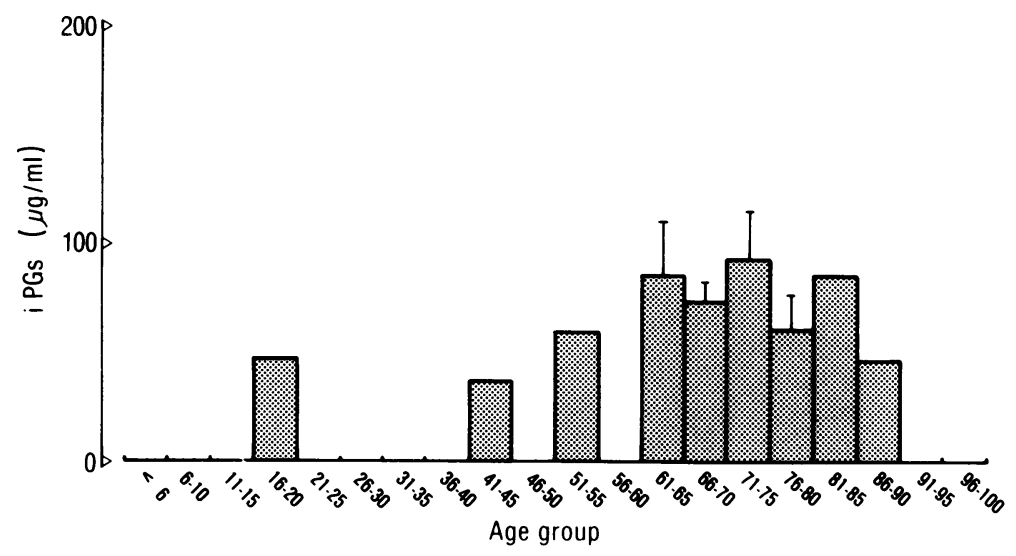

Fig. 2 Distribution of $(A)$ glycosaminoglycan $(G A G)$ and (B) immmunoreactive proteoglycan ( $i P G$ ) concentrations according to age in patients with rheumatoid arthritis and osteoarthritis. Bars denote

standard deviations where $n>3$.

Table 2 Age, synovial fluid volume, concentrations of sulphated glycosaminoglycans (GAGs) and immunoreactive proteoglycans ( $i P G s)$, and the total amount of sulphated GAGs and iPGs in the knee joints of patients with osteoarthritis $(O A)$, rheumatoid arthritis $(R A)$, gout, and Reiter's syndrome $(R S)^{*}$

\begin{tabular}{|c|c|c|c|c|}
\hline & $\begin{array}{l}O A \\
(n=22)\end{array}$ & $\begin{array}{l}R A \\
(n=2 I)\end{array}$ & $\begin{array}{l}\text { Gout } \\
(n=13)\end{array}$ & $\begin{array}{l}R S \\
(n=5)\end{array}$ \\
\hline Age of patient (years) & $72 \cdot 0(1 \cdot 7)$ & $59.9(3.4)$ & $49 \cdot 0(5 \cdot 0)$ & $24 \cdot 6(1 \cdot 5$ \\
\hline $\begin{array}{l}\text { Volume of synovial fluid (ml) } \\
\text { iPGs }\end{array}$ & $13 \cdot 8(2 \cdot 1)$ & $25 \cdot 2(4 \cdot 8)$ & $38 \cdot 8(13 \cdot 1)$ & $17 \cdot 6(4 \cdot 7$ \\
\hline$\mu \mathrm{g} / \mathrm{ml}$ & $71(5)$ & 81 (17) & $185(28)$ & $310(59)$ \\
\hline $\mathrm{mg} /$ joint & $0.9(0 \cdot 1)$ & $2 \cdot 2(0 \cdot 6)$ & $6 \cdot 4(2 \cdot 0)$ & $6.6(1.6$ \\
\hline \multicolumn{5}{|l|}{ Sulphated GAGs } \\
\hline$\mu \mathrm{g} / \mathrm{ml}$ & $101(6)$ & $127(15)$ & $259(38)$ & $282(86)$ \\
\hline $\mathrm{mg} /$ joint & $1.4(0 \cdot 2)$ & $3 \cdot 3(0 \cdot 7)$ & $7 \cdot 4(2 \cdot 3)$ & $5 \cdot 5(2 \cdot 4$ \\
\hline
\end{tabular}

*Values are mean (SEM). 
synovial fluid aspirated and the total quantity of iPGs and sulphated GAGs in the joint cavity.

The concentrations of iPGs were found to be highest in Reiter's syndrome and gout. Values in Reiter's syndrome were significantly higher than in RA $(p<0.001)$ and OA $(p<0.001)$. The values in gout were also significantly higher than in RA $(\mathrm{p}<0.01)$ and $\mathrm{OA}(\mathrm{p}<0.001)$. Significant differences were not observed between OA and RA or Reiter's syndrome and gout.

TOTAL IPGs IN THE JOINT CAVITY

A very similar distribution of results was obtained when the total quantity of iPGs in the joint cavity was determined in the four diseases under study. Total iPGs were found to be highest in the joints of patients with Reiter's syndrome and gout. The iPG content of the joints in patients with Reiter's syndrome was significantly higher than that in patients with OA $(p<0.002)$ and RA $(p<0.05)$. The iPG content in the joints of patients with gout was also significantly higher than in patients with $\mathrm{OA}$ $(p<0.002)$ and RA $(p<0 \cdot 02)$. No significant difference was observed between OA and RA or gout and Reiter's syndrome.

CONCENTRATIONS OF SULPHATED GAGS Concentrations of sulphated GAGs were found to be highest in gout and Reiter's syndrome as was the case for iPGs. In Reiter's syndrome the sulphated GAG concentrations were significantly higher than those in OA $(p<0.001)$ and RA $(p<0.01)$. Sulphated GAG concentrations in gout were also significantly higher than those in OA $(\mathrm{p}<0.001)$ and RA ( $<<0.001)$. Significant differences were not observed between $O A$ and RA or between gout and Reiter's syndrome.

TOTAL QUANTITY OF SULPHATED GAGs IN THE JOINT CAVITY

The total quantity of sulphated GAGs was found to be significantly higher in gout than in RA $(p<0.05)$ and OA $(p<0.01)$, but not Reiter's syndrome. In RA and Reiter's syndrome the total quantity of sulphated GAGs was significantly higher than in OA $(p<0 \cdot 05)$. No significant difference was observed between Reiter's syndrome and RA. The distribution of results observed for total iPGs and total sulphated GAGs was very similar.

RATIO OF SULPHATED GAGs TO IPGs

The ratio sulphated $\mathrm{GAG} / \mathrm{iPG}$ was determined for each of the diseases studied and compared with that obtained for normal synovial fluid (Fig. 1). In RA the ratio was significantly higher than in $\mathrm{OA}$ $(\mathrm{p}<0.01)$, gout $(\mathrm{p}<0.02)$, Reiter's syndrome $(p<0 \cdot 01)$, and normal synovial fluid $(p<0 \cdot 05)$. No significant difference was observed between the ratios for $\mathrm{OA}$ and gout or Reiter's syndrome and normal synovial fluid. The ratio for normal synovial fluid was significantly lower than that for $\mathrm{OA}$
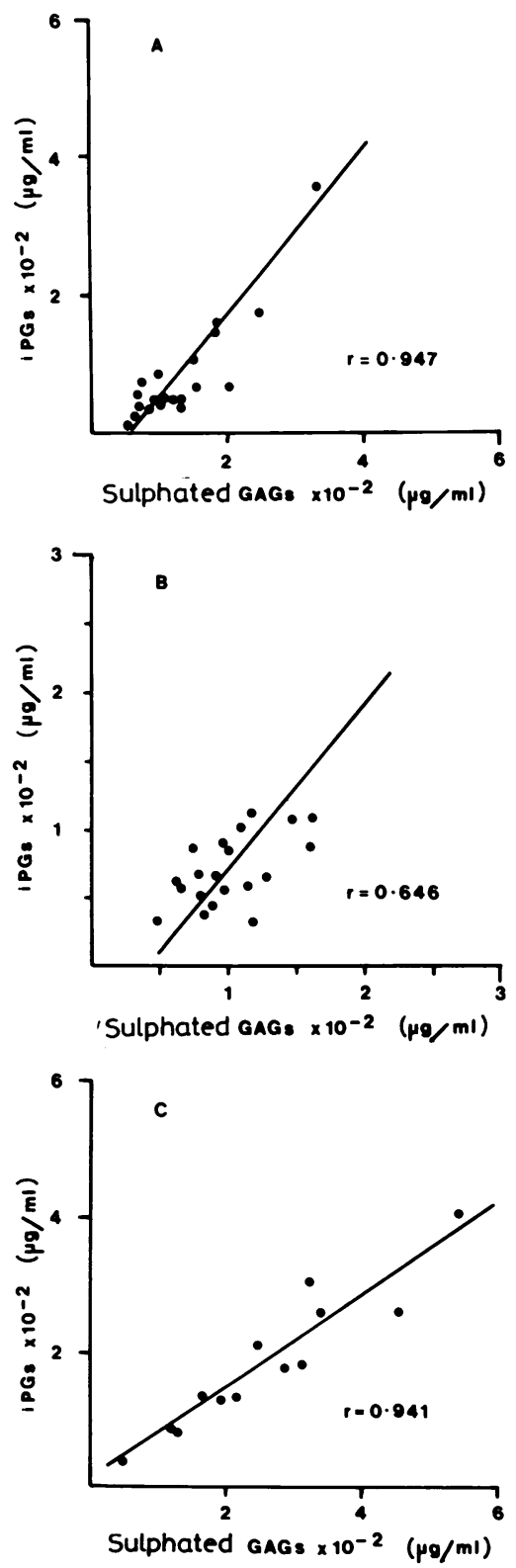

Fig. 3 Correlation between the concentrations of sulphated glycosaminoglycans (GAGs) and immunoreactive proteoglycans ( $i P G s$ ) in synovial fluid obtained from the knee joints of patients with $(A)$ rheumatoid arthritis, $(B)$ osteoarthritis, and $(C)$ gout. 
$(\mathrm{p}<0.02)$ and gout $(\mathrm{p}<0.001)$. Likewise, the ratio for Reiter's syndrome was significantly lower than that for OA $(p<0.002)$ and gout $(p<0.001)$. In normal synovial fluid the ratio sulphated GAG/iPG was found to approximate unity closely and there was very little dispersion among the five results. These findings suggest the presence of a population of proteoglycans in which the hyaluronic acid binding region is highly conserved. Such a population may represent monomers which have been secreted by the articular chondrocytes but not incorporated into the cartilage matrix.

RELATION BETWEEN TOTAL SULPHATED GAGS AND IPG CONCENTRATIONS

The degree of correlation between the concentrations of total sulphated GAGs and iPGs was determined for each of the diagnostic categories. Figure 3 shows the results for RA, OA, and gout. A strong positive linear correlation was observed in gout $(\mathrm{r}=0.941)$. A good linear correlation was also observed in RA $(r=0.947)$ and OA $(r=0.646)$. A

Table 3 Relation between sulphated GAG or iPG concentrations and the inflammatory cell infiltrate in synovial fluids from patients with rheumatoid arthritis and gout

\begin{tabular}{|c|c|c|c|}
\hline & \multirow{2}{*}{$\begin{array}{l}\text { Number of } \\
\text { cells } \times \\
10^{-9} / l\end{array}$} & \multicolumn{2}{|c|}{$\begin{array}{l}\text { Spearman correlation } \\
\text { coefficient }(r)\end{array}$} \\
\hline & & $\begin{array}{l}\text { Sulphated } \\
\text { GAGs }\end{array}$ & iPGs \\
\hline \multicolumn{4}{|c|}{$\begin{array}{l}\text { Rheumatoid arthritis } \\
(n=18)\end{array}$} \\
\hline PMNs $\dagger$ & $8.8(1.9)^{*}$ & 0.456 & $0 \cdot 229$ \\
\hline MNCs $\dagger$ & $2 \cdot 2(0 \cdot 3)$ & 0.447 & $0 \cdot 470$ \\
\hline \multicolumn{4}{|c|}{ Gout $(n=9)$} \\
\hline PMNs & $14 \cdot 1(6 \cdot 2)$ & 0.431 & $0 \cdot 206$ \\
\hline MNCs & $1.6(0.6)$ & $0 \cdot 354$ & 0.252 \\
\hline
\end{tabular}

good correlation was also observed in Reiter's $\Rightarrow$ syndrome $(r=0.958)$, but the sample number was small.

RELATION BETWEEN LEUCOCYTE

POPULATIONS AND CONCENTRATIONS OF SULPHATED GAGS AND IPGS IN SYNOVIAL FLUID Leucocyte counts were performed on most specimens of synovial fluid and the cells were classified as $\vec{\omega}$ either polymorphonuclear leucocytes or mononuclear leucocytes. Table 3 shows that the concentrations of sulphated GAGs and iPGs did not ${ }_{\infty}^{+}$ correlate closely with the number or type of leucocytes in the synovial fluid.

RELATION BETWEEN THE CONCENTRATION OF SULPHATED GAGs, iPGs, AND

RADIOLOGICAL SEVERITY IN RA

Sixteen of the 21 patients with RA had knee radiographs which met the inclusion criteria. An analysis of the $x$ rays showed Larsen-Dale indices $\vec{c}$ ranging from 0 to 3 with a median index of 2 . As the number of patients in each grade was small patients with grades 0 or 1 and 2 or 3 were pooled to allowo comparison between those with trivial or no loss of cartilage and those with mild or moderate cartilage loss. Table 4 gives the results of this analysis. It can be seen that the concentrations of sulphated GAGs and iPGs did not differ between the two groups. $A \overrightarrow{\overrightarrow{0}}$ trend towards higher total quantities of sulphated GAGs and iPGs was observed in the group with grade 2 or 3 radiographs. This finding reflects differences in effusion volume, which were not $\frac{0}{2}$ statistically significant. A higher mean sulphated $d_{\sigma}^{\circ}$ GAG/iPG ratio was observed in the patients with 3 more severe RA, but this difference also was not statistically significant.

\section{Discussion}

It is clear from recent studies that proteoglycans can be readily detected in arthritic joint synovia. ${ }^{6} \varangle-12$ In $N$

Table 4 Concentrations, total quantity, and ratio of sulphated GAGs to iPGs in synovial fluids obtained from the knee joints of patients with $R A$ of differing severity

\begin{tabular}{|c|c|c|c|c|c|}
\hline $\begin{array}{l}\text { Radiological } \\
\text { severity }\end{array}$ & $\begin{array}{l}\text { Sulphated GAGs } \\
(\mu g / m l)\end{array}$ & iPGs $(\mu g / m l)$ & $\begin{array}{l}\text { Total sulphated } \\
G A G s(\mu g / m l)\end{array}$ & $\begin{array}{l}\text { Total iPGs } \\
(\mu \mathrm{g} / \mathrm{ml})\end{array}$ & Sulphated $G A G / i P G$ \\
\hline $\begin{array}{l}0 \text { or } 1 \quad(n=6) \\
2 \text { or } 3 \quad(n=10) \\
\text { Significance } t\end{array}$ & $\begin{array}{l}121 \cdot 5(21 \cdot 6)^{*} \\
116 \cdot 2(18 \cdot 8) \\
\text { NS }\end{array}$ & $\begin{array}{l}68 \cdot 2(9 \cdot 9) \\
63 \cdot 2(18 \cdot 4) \\
\text { NS }\end{array}$ & $\begin{array}{l}1870(581) \\
3706(1128) \\
\text { NS }\end{array}$ & $\begin{array}{l}942(280) \\
2042(806) \\
\text { NS }\end{array}$ & $\begin{array}{l}1.84(0.27) \\
2.66(0.44) \\
\text { NS }\end{array}$ \\
\hline
\end{tabular}


some diseases these proteoglycans have already been partially characterised. ${ }^{6} 1012$ Most, if not all, of the proteoglycans in synovial fluid are considered likely to be cartilaginous in origin as their hydrodynamic size is consistent and they react with cartilage specific antisera, including monoclonal antibodies which react with keratan sulphate related epitopes. It should be noted, however, that synovial tissue is also capable of producing proteoglycans. ${ }^{22-24}$

In this study two different types of assay were used to measure cartilage degradation products in synovial fluid. The modified dimethylmethylene blue assay was used to measure sulphated GAGs and a radioimmunoassay was used to measure immunoreactive cartilage proteoglycans. Sulphated GAGs are neither restricted to proteoglycans nor specific for cartilage, but they are relatively stable in synovial fluid and it is considered unlikely that they undergo significant degradation when proteoglycans are released from cartilage. In contrast, proteolysis is likely to occur during the release of bound proteoglycan monomers from cartilage and further degradation may also occur in the synovial fluid. It is therefore possible that in some instances critical epitopes may be destroyed, hindering detection.

The antiserum used for the radioimmunoassay contains antibodies directed against the hyaluronic acid binding region of intact proteoglycan monomers and is therefore capable of recognising intact monomers and fragments in which the hyaluronic acid binding region has been conserved, but not cleaved fragments which do not contain such a region. ${ }^{21}$ The antibodies also vary in their affinity for proteoglycans depending upon whether the molecules are bound to hyaluronic acid. ${ }^{25}$ Bound proteoglycans are preferentially recognised. In view of these limitations the antiserum is not ideal for accurate measurement of proteoglycans in synovial fluid. As it is specific for the hyaluronic acid binding region, however, it is likely to recognise proteoglycans derived from articular cartilage.

In gout and Reiter's syndrome the concentrations of sulphated GAGs and iPGs were found to be significantly higher than in OA and RA. Similar differences were evident when comparisons were made for the total quantities of sulphated GAGs and iPGs in the four disease groups. These results confirm those of Saxne et al, who have shown that in Reiter's syndrome the concentration and total quantity of iPGs are significantly higher than in RA. ${ }^{8}$ It should be noted that the different concentrations of iPGs and sulphated GAGs observed in RA and Reiter's syndrome cannot be explained on the basis of the size of the effusions as these do not differ significantly. Furthermore, analysis of the results for other disease groups provides no evidence for a dilutional effect associated with increasing effusion volume. Comparison of the total quantity of iPGs and sulphated GAGs in the joints of patients with different diseases shows that these quantities follow the same trend as the concentrations. In some instances, however, such as OA and RA, the magnitude of the difference is enhanced by the substantial difference in effusion volume.

In patients with RA no relation was observed between the concentrations of sulphated GAGs or iPGs and the degree of cartilage loss as judged radiologically. These results differ from those of Saxne $e t a l$, who found that the concentrations of proteoglycans decreased with increasing disease severity. ${ }^{8}$ It should be noted that the sample number in this study was only 16 , which is considerably smaller than that of Saxne et al. Furthermore, in this study there were no patients with Larsen-Dale indices greater than 3 . In the study reported by Saxne et al the inverse relation between the concentrations of proteoglycans and disease severity was most apparent in patients with Larsen-Dale indices of 4 and 5 . Thus the results reported here neither confirm nor refute the previously observed relationship.

In gout a strong correlation was observed between sulphated GAGs and iPGs. Moreover, there was very little variation in the sulphated GAG/iPG ratio. These results imply strong conservation of the structural relation between the sulphated GAGs and the hyaluronic acid binding region of the proteoglycans in gouty synovial fluid. In $\mathrm{OA}$ and RA the variation in the sulphated GAG/iPG ratio and poorer correlation between the sulphated GAG and iPG concentrations indicate greater heterogeneity among the synovial fluid proteoglycans in these diseases. It is of interest that in RA the sulphated GAG/iPG ratio was significantly higher than in normal synovial fluid and the other diseases studied. The ratio was also significantly higher than that obtained for the intact proteoglycan monomers prepared from normal human articular cartilage. Gysen et al have shown that there is a high proportion of small proteoglycan fragments in rheumatoid synovia, ${ }^{26}$ and more recently Witter $e t$ al have demonstrated highly disperse populations of proteoglycan fragments in $\mathrm{RA}$ synovial fluid. ${ }^{12}$ In the latter study some of the proteoglycan fragments contained hyaluronic acid binding region epitopes, whereas others rich in keratan sulphate did not. These findings suggest that different catabolic mechanisms may be operating in the diseases studied. More detailed examination of the nature of the proteoglycan molecules in normal and pathological synovial fluid could help to elucidate these mechanisms further. 
I thank Dr D Fatehee and $\mathrm{Mr} \mathrm{M}$ Bell for valuable technical assistance, Dr A R Poole for the rabbit proteoglycan antiserum, Professor P Ghosh for a sample of human cartilage proteoglycan. and Eileen Whitehead for her secretarial services. I also thank the Western Australian Arthritis and Rheumatism Foundation and the Royal Perth Hospital Research Foundation for their generous financial support.

\section{References}

1 Heinegård D, Paulsson $M$. Structure and metabolism of proteoglycans. In: Piez K, Reddi H, eds. Extracellular matrix biochemistry. New York: Elsevier/North Holland, 1984: 277328.

2 Bayliss M J, Ali S Y. Age-related changes in the composition and structure of human articular-cartilage protcoglycans. Biochem J 1978; 176: 683-93.

3 Roughley P J, White R J. Age-related changes in the structure of the proteoglycan subunits from human articular cartilage. $J$ Biol Chem 1980; 225: 217-24.

4 Edwards C G, Chrisman O D. Articular cartilage. In: Albright J A, Brand R A, eds. The scientific basis of orthopaedics. New York: Appleton-Century-Crofts, 1979: 313-47.

5 Dingle J T, Horsfield $\mathrm{P}$, Fell $\mathrm{H}$ B, Barratt M E J. The breakdown of proteoglycan and collagen induced in pig articular cartilage in organ culture. Ann Rheum Dis 1975; 34: 303-11.

6 Gysen P. Franchimont P. Radioimmunoassay of proteoglycans. J Immunoassay 1984; 5: 221-43.

7 Malik S C, Pearson J P. Dick C W. A comparison of glycosaminoglycans content of human synovial fluid in different disease states. Biochem Soc Trans 1984; 12: 874

8 Saxne $T$, Wollheim, $F A$, Heinegård $D$, Pettersson $H$. Difference in cartilage proteoglycan level in synovial fluid in early rhcumatoid arthritis and reactive arthritis. Lancet 1985; ii: $127-8$.

9 Saxne T, Heinegård D, Wollheim F A. Therapcutic effects on cartilage metabolism in arthritis as measured by release of proteoglycan structures into the synovial fluid. Ann Rheum Dis 1986; 45: 491-7.

10 Carroll G J. Spectrophotometric measurement of proteoglycans in osteoarthritic synovial fluid. Ann Rheum Dis 1987; 46: 375-9.

11 Saxne T, Heinegård D, Wollheim F A. Cartilage proteoglycans in synovial fluid and serum in patients with inflammatory joint disease. Arthritis Rheum 1987; 30: 972-9.

12 Witter J, Roughley P J. Webber C, Roberts R. Keystone E. Poole A R. The immunologic detection and characterisation of cartilage proteoglycan degradation products in synovial fluids of patients with arthritis. Arthritis Rheum 1987: 30: 519-26.

13 Dingle J T, Page Thomas D P, Hazleman B. The role of cytokines in arthritic disease: in vitro and in vivo measurements of cartilage degradation. Int J Tissue React 1987: 9: 349-54.

14 Ropes M W. Bennett G A. Cobb S, Jacox R. Jessar R A. Revision of diagnostic criteria for rheumatoid arthritis. Ann $\mathbb{\nabla}$ Rheum Dis 1959; 18: 49-53.

15 Willkens R F. Arnett F C. Bitter T, et al. Reiter's syndrome: कै evaluation of preliminary criteria for definite discase. Bull Rheum Dis 1982; 32: 31-4

16 Wallace S L, Robinson H, Alfonse T M. et al. Preliminary criteria for the classification of the acute arthritis of primary gout. Arthritis Rheum 1977; 20: 895-9(00.

17 Altman R, Asch E, Bloch D. Development of criteria for the classification and reporting of osteoarthritis. Arthritis Rheum : 1986; 29: 1039-49.

18 Larsen A Dale K. Eek M. Radiographic evaluation of rheumatoid arthritis and related conditions by standard reference films. Acta Radiol (Diagn/ (Stockh) 1977; 18: 481-91.

19 Farndale R W, Buttle D J, Barrett A J. Improved quantitation and discrimination of sulphated glycosaminoglycans by use of dimethylmethylene blue. Biochem Biophys Acta 1986; 883: $c$ 173-7.

20 Christner J E, Caterson B, Baker J R. Immunological determinants of proteoglycans. J Biol Chem 1980; 255: 7102-5.

21 Kimura J H, Thonar E J-M, Hascall V C, Reiner A. Poole A R. Identification of core protein, an intermediate in proteoglycan 0 biosynthesis in cultured chondrocvtes from the Swarm rate chondrosarcoma. J Biol Chem 1981; 256: 7890-7.

22 Marsh J M, Wicbkin O W. Gale S, et al. Synthesis of sulphated proteoglycans by rheumatoid and normal synovial tissue in culture. Ann Rheum Dis 1979: 38: 166-70.

23 Fife R S, Myers S L. Evidence for an interaction betweeng synovial cell proteoglycans and link proteins. Biochim Biophys Acta 1985 ; 843: 238-44.

24 Hamerman D. Smith C, Keiser H D. Craig R. Glycosamino- $\vec{B}$ glycans produced by human synovial cell cultures. Coll Relat Res 1982; 2: 313-29.

25 Thonar E J-M. Kimura J H. Hascall V C. Poolc A R. Enzymclinked immunosorbent assay analyses of the hyaluronatebinding region and the link protein of proteoglycan aggregate. Biol Chem 1982; 257: 14173-80.

26 Gysen P. Malaise M. Gaspar S, Franchimont P. Measurement of proteoglycans, elastase, collagenase and protein in synovial fluid in inflammatory and degenerative arthropathies. Cliti Rheumatol 1984; 4: 39-50. 